\section{HOW TO USE A MEDICAL} \section{LIBRARY}

By Leslie T. Morton.

John Bale, Sons \& Danielsson, Ltd., 1934.

Price 2/6.

We cordially welcome this little volume which will be a real boon to the younger medical man who is commencing his career as a serious student of medicine and contributor to the literature. His predecessors had to gain much of the information which it contains at the expense of prolonged and often sad experience. From its perusal the reader will obtain, in addition to much sound advice on the writing of papers, information regarding how to obtain knowledge of previous work without which the author justly remarks no man has the right to put pen to paper.

The correct method of compiling a bibliography, which is the stumbling block of most authors and the bane of most editors, is described in detail so that little difficulty should be experienced in putting the proper period to any literary production. As one appendix there is supplied a list of Medical Journals which provide abstracts and epitomes of current articles and books, and as another a list of the various medical libraries in the country.
For such a small volume the index seems remarkably full, but this, of course, ensures that it serves as a ready book of reference.

\section{BLOOD DISEASES IN GENERAL PRACTICE}

\author{
By A. Piney.
}

John Bale, Sons \& Danielsson, Ltd., London. 1934. Price $2 / 6$ net.

In this small volume there is considered in an eminently practical fashion the diseases of the blood in view of modern developments. Since the work is intended primarily for the general practitioner the clinical appearances of, and the therapeutic measures available in, the different types of blood disease are chiefly detailed, the blood pictures receiving only scant consideration. This we feel is the weakness of the work, since if this aspect of the subject had been supplied it would render the hæmatological reports of the clinical pathologist intelligible to the practitioner as well as making the book more generally useful.

\title{
Miscellaneous.
}

This Section deals with New Drugs, Preparations, Surgical Instruments, etc. The description of each article is supplied by the Producer. Particulars regarding insertions, which are free of cost, may be obtained from the Business Manager, Fellowship of Medicine and Post-Graduate Journal, 553, Grand Buildings, W.C.2.

A well produced booklet issued by Boots Pure Drug Co., Ltd. deals with Medicinal Glucose (Anhydrous) Dex-

Boots Pure trose B.P. Advantages of Drug Co. Ltd. glucose as a therapeutic agent are stressed. It is readily soluble and is quite stable. It has a high calorific value and its taste is not objectionable. It does not affect the appetite and does not produce nausea, even when taken between meals.

A number of interesting case reports are quoted in full and there is evidence to prove that treatment has been undertaken successfully in such differing conditions as acute gastro-enteritis, carbohydrate starvation, diphtheria, gastric ulcer, migraine, pneumonia, sea-sickness, surgical shock and vomiting of pregnancy.

Boots Pure Drug Co. Ltd. have also published an informative pamphlet on Gonococcus Vaccines. They have arranged to be supplied at regular intervals with a full range of gonococcus vaccines made in the department for Venereal Diseases at St. Thomas's Hospital. These vaccines are supplied in bulk by the hospital and are filled into ampoules and vials in the Boots' Laboratories by approved methods and under scientific control. Each batch is tested bacteriologically before issue. 